\title{
Self-reported experience of orofacial injury, preventive practice, and knowledge of Iranian adolescent martial art athletes towards sports-related orofacial injuries
}

\author{
Ali Esmaeilpoor', Simin Z. Mohebbi ${ }^{2,3}$, Navid Moghadam ${ }^{4,5}$, Mina Ahmadian ${ }^{6}, S^{2}$ amaneh Razeghi ${ }^{2,3^{*}}$ and
} Mohammad R. Khami ${ }^{2,3}$

\begin{abstract}
Background: Increased engagement of adolescents in martial arts exposes them to a relatively high risk of experiencing orofacial injuries. We evaluated self-reported experience of orofacial injuries, preventive practice, and knowledge of management of sport-related orofacial injuries and related factors in adolescent Karate and Taekwondo athletes in Iran.
\end{abstract}

Methods: This cross-sectional study was conducted on Iranian martial arts athletes including Karate and Taekwondo aged 11-17-year-old in 2020 via an online questionnaire. The anonymous self-administrated questionnaire had four parts: background (age, gender, duration of sports activity, training sessions per week, and previous education on orofacial injury); self-reported experience of orofacial injury; preventive practice including mouthguard and helmet use; and knowledge of emergency management of orofacial injuries. Preventive practice and knowledge scores were calculated by summing up the scores of corresponding questions (possibly range $0-7$ ). A linear regression model and the Pearson correlation served for statistical analysis.

Results: Totally, 295 athletes with a mean age of $14.56 \pm 1.91$ years participated in the study. A quarter ( $n=74,25.1 \%$ ) of athletes stated that they had received training on prevention of orofacial injuries. Only $3.7 \%(n=11)$ of the participants reported the use of custom-made mouthguards, and $62 \%(n=183)$ reported a positive history of orofacial injuries. A significant relationship existed between self-reported orofacial injury and age $(\beta=-0.32, p<0.001)$, hours of training per week $(\beta=0.12, p=0.037)$, type of sport $(\beta=0.11, p=0.049)$, and previous training on orofacial injuries $(\beta=-0.14, p=0.010)$. No difference existed in the history of orofacial injury between females $(n=114)$ and males $(n=69)(p=0.374)$. The mean score of self-reported preventive practice and knowledge of management of orofacial injuries was $3.53 \pm 1.82$ (out of 7 ) and $1.67 \pm 1.10$ (out of 7 ), respectively. Age $(\beta=0.19, p=0.002$ ) and history of orofacial injury $(\beta=-0.15, p=0.010$ ) were associated with the score of self-reported preventive practice. Female athletes $(\beta=0.11, p=0.048)$ and athletes who exercised more per week $(\beta=0.15, p=0.012)$ had significantly more knowledge on management of orofacial injuries.

*Correspondence: s-razeghi@tums.ac.ir

3 Department of Community Oral Health, School of Dentistry, Tehran

University of Medical Sciences, Tehran, Iran

Full list of author information is available at the end of the article

(c) The Author(s) 2021. Open Access This article is licensed under a Creative Commons Attribution 4.0 International License, which permits use, sharing, adaptation, distribution and reproduction in any medium or format, as long as you give appropriate credit to the original author(s) and the source, provide a link to the Creative Commons licence, and indicate if changes were made. The images or other third party material in this article are included in the article's Creative Commons licence, unless indicated otherwise in a credit line to the material. If material is not included in the article's Creative Commons licence and your intended use is not permitted by statutory regulation or exceeds the permitted use, you will need to obtain permission directly from the copyright holder. To view a copy of this licence, visit http://creativecommons.org/licenses/by/4.0/. The Creative Commons Public Domain Dedication waiver (http://creativeco mmons.org/publicdomain/zero/1.0/) applies to the data made available in this article, unless otherwise stated in a credit line to the data. 
Conclusion: Adolescent athletes had relatively undesirable preventive practices and a distinct lack of knowledge. The high occurrence of self-reported orofacial injuries indicates the importance of more education and stricter rules for the athlete population.

Keywords: Contact sports, Orofacial injuries, Adolescent

\section{Background}

Orofacial injuries are a significant public health problem due to their relatively high frequency in the society and the extensive impact they may have on a person's quality of life [1,2]. Children and adolescents are a high-risk group for orofacial injuries [3]. In a metaanalysis by Petti et al. [1], nearly one in five children aged 11-13 years had a history of traumatic dental injuries (TDIs); moreover, males were more likely to experience traumatic dental injuries (TDIs) than females [1]. Based on the results of the latest national oral health survey in Iran, about $5 \%$ of the 12 -year-old and $6 \%$ of the 15-year-old Iranians experienced TDIs, which were more prevalent in boys in both age groups [4].

Increased participation in sports activities comes with a significant risk of sustaining orofacial injuries. On the other hand, the popularity of martial arts in combat form in both genders and the engagement of children and young adults in such sports expose them to a relatively high risk of experiencing orofacial injuries at an early age [5-8]. Fortunately, most sportsrelated orofacial injuries are preventable through using equipment such as mouthguards, facemasks and helmets [9]. In a systematic review, Knapik et al. found that using mouthguards during sports activities reduced the risk of orofacial injuries [10]. Furthermore, the American Dental Association and the Academy for Sports Dentistry have recommended the use of custom-fitted mouthguards in all activities with a risk of orofacial injuries $[5,9,11,12]$.

American Academy of Pediatric Dentistry has stated that falls, collisions, contact with hard surfaces, and contact from sports-related equipment poses an associated risk of orofacial injuries with all sporting activities [9]. Martial arts include a variety of formal traditions selected by athletes for self-defense, competition, physical fitness, motor development, and emotional growth $[13,14]$. There are both noncombat forms with less risk of injury, and combat forms with increased potential for injury [13]. Taekwondo and Karate are two popular disciplines of martial arts among Iranian adolescents [15, 16]. Iranian children and adolescents of both genders in different age groups regularly practice these two martial arts, which belong to the group of contact sports and may lead to injury to the athletes not only during competitions but also in training sessions $[15,16]$.
Some domestic studies have evaluated orofacial injuries in martial arts and showed that the prevalence of head and neck injury was relatively high in comparison with other types of injuries. For instance, Ziaee et al. found that in Karate, $61 \%$ of all injuries were located in the head and neck area in athletes younger than 30 years old [16]. In another study by Halabchi et al., 55.4\% of all injuries were located in the head, neck and face in female Karate athletes [7]. Moreover, Ziaee et al. reported that head and neck injuries accounted for about $7.5 \%$ of all injuries in male black-belt taekwondo competitors aged $17-32$ years old [15].

Considering the sparse data on the knowledge of orofacial injury prevention and mouthguard use in Iranian adolescent martial arts athletes and to establish effective educational strategies for orofacial injuries in this highrisk group, the present study was conducted to evaluate self-reported experience of orofacial injuries and related factors, self-reported preventative practice, and knowledge of the management of sports-related orofacial injuries in 11-17 year-old Karate and Taekwondo athletes in Iran in 2020.

\section{Materials and methods \\ Sampling and data collection}

This descriptive-analytical cross-sectional study was conducted on 11-17-year-old Karate and Taekwondo athletes in Iran in 2020. This age group was selected since there is a general notion that adolescents experience accidental injuries during contact sports [17]; moreover, it has been shown that a small proportion of young athletes in diverse sport activities are aware of the importance of using mouthguards among them only 3\% actually used them [18]. Additionally, increased participation of females in sports and their similar exposure to the risk factors compared with males $[19,20]$ were the reasons for recruitment of adolescent athletes of both genders. Among different martial arts, Karate and Taekwondo have the highest number of athletes in both genders in Iran.

Based on a previous study indicating a prevalence of $61 \%$ for head and neck injuries [16] and considering $\alpha=0.05$ and $\beta=0.8$, the minimum sample size was estimated at 253 .

All contact sports clubs were closed in Iran at the time of data collection due to the COVID-19 pandemic. 
Therefore, the athletes were surveyed via an online questionnaire prepared in Google Docs (Google Inc., Googleplex, Mountain View, California, USA). After coordination with Taekwondo and Karate federations, the Public Relations of both federations published the link of the online questionnaire in their social networks (WhatsApp Inc., Mountain View, California, USA). This link was provided to athletes on a daily basis for a week from 8 to 15th September 2020. Two reminders were sent in the social networks during this period. Participation in the study was voluntary. All participants were informed about the objectives of the study; therefore, those who were willing to participate in the study filled out the questionnaire.

The inclusion criteria were (1) male or female gender, (2) age 11 and 17 years old, and (3) being a member of the official social network of Taekwondo or Karate Federation. Gender and age of participants were self-reported through the self-administrated questionnaire; and access to members of the official social network of Taekwondo or Karate Federation was through the Public Relations of both federations. The only exclusion criterion was reluctance to participate in the study.

\section{Questionnaire}

An anonymous self-administrated questionnaire was adopted from previous studies [11, 21, 22]. After collecting the questions, a panel of experts including two community oral health experts, one pediatric dentist, one sport medicine specialist, and one epidemiologist assessed the content validity of the questionnaire. The reliability of the questionnaire was assessed through a test-retest approach on 10 Taekwondo athletes at an interval of 10 days. These athletes were excluded from the main study. The Kappa coefficient ranged from 0.71 to 0.93 for different questions which means a good testretest reliability [23].

The questionnaire was in Farsi and comprised four parts as follows:

- Background information (age, gender, years of practice, number and duration of training sessions per week, and previous training on prevention and management of orofacial injury);

- Self-reported experience of orofacial injury: a "yes/ no" question

- Self-reported preventive practice: five questions on the use of protective gear (mouthguard and helmet) using multiple-choice as well as "yes, no, and I do not know" answers. Unfavorable and "I do not know" answers were scored 0 and favorable answers were scored 1 . One question on the type of athlete mouthguard had weighted scores based on the answers (custom-made $=3, \quad$ mouth-formed $=2, \quad$ stock $=1$, not using $=0$ ). The self-reported preventive practice score of each athlete was calculated through summing up the scores of five questions (range: 0-7) [24, 25]. A multiple-choice question addressed the reasons for not using the mouthguard.

- Knowledge of emergency management of orofacial injuries: seven questions with multiple-choice and "yes, no, and I do not know" answers. A score of 0 was given to false or "I do not know" answers and a score of 1 was assigned to correct answers. The knowledge score of each athlete was calculated by summing up the scores of the seven questions (range: $0-7)[24,25]$.

Based on achievable range of scores, the level of both self-reported preventive practice, and knowledge of respondents were categorized as inadequate $(0-3)$, moderate $(>3$ and $<5)$, and adequate $(>5)$.

\section{Ethics}

Ethical approval was obtained from the Ethics Committee of Tehran University of Medical Sciences (IR.TUMS. DENTISTRY.REC.1399.016). All steps of the study were performed in accordance with the Declarations of Helsinki. The study was voluntary and the responses were anonymous. All the participants were informed about the objectives of the study. Informed consent was obtained from participants and their parents via a link sent to the parent's cellphone.

\section{Statistical analysis}

After collecting the questionnaires, the answers were scored and the results were analyzed using descriptive statistics, Backward linear regression model, and Pearson correlation coefficient. Backward linear regression model was used to determine the effects of selected independent variables on athletes' self-reported experience of orofacial injuries, self-reported preventative practice, and knowledge of the management of sports-related orofacial injury, as multivariate analysis. The association between self-reported practice and knowledge was explored using the Pearson correlation coefficient. P-values less than 0.05 were considered statistically significant. Data analysis was performed using SPSS version 25 (Chicago, IL, USA).

\section{Results}

In total, 295 questionnaires were collected. The mean age of the participants was $14.56 \pm 1.91$ years old. Totally, $59.0 \%$ of the participants $(n=147)$ were female, and $78.0 \%(\mathrm{n}=230)$ did Taekwondo. The average duration of practicing these sports was $5.02 \pm 2.77$ years, and 230 
(78.0\%) athletes had more than three years of experience. Of all the participants $56.6 \%(n=167)$ trained more than $5 \mathrm{~h}$ per week. Of all the participants who completed the questionnaires, 74 (25.1\%) stated that they had received training on prevention of orofacial injuries. Table 1 shows the characteristics of the study participants based on the sport.

One hundred and eighty-three subjects (62\%) reported a positive history of orofacial injuries. There was, however, no significant difference in the history of orofacial injuries between genders (females: $n=114,65.5 \%$, males: $\mathrm{n}=69,57 \%)(p=0.37)$. A significant relationship was found between self-reported experience of orofacial injury and age $(\beta=-0.32, p<0.001)$, hours of training per week $(\beta=0.12, p=0.037)$, and previous training on prevention and management of orofacial injuries $(\beta=-0.14, p=0.010)$. Taekwondo players reported significantly more self-reported experience of orofacial injuries compared to Karate players $(\beta=0.11, p=0.049)$ (Table 2).

Of all participants, $71.5 \%(n=211)$ indicated that they usually used a mouthguard during practice or a match. The most common types of mouthguards used by

Table 1 Characteristics of the study participants $(n=295)$

\begin{tabular}{lccc}
\hline & $\begin{array}{l}\text { Karate } \\
\mathbf{n}(\%)\end{array}$ & $\begin{array}{l}\text { Taekwondo } \\
\mathbf{n}(\%)\end{array}$ & $\begin{array}{c}\text { Total } \\
\mathbf{n}(\%)\end{array}$ \\
\hline $\begin{array}{l}\text { Gender } \\
\text { Male }\end{array}$ & & \\
Female & $24(36.9)$ & $97(42.2)$ & $121(41.0)$ \\
Number ofyears of sport experience & $133(57.8)$ & $174(59.0)$ \\
$<3$ years & $13(4.4)$ & $52(17.6)$ & $65(22.0)$ \\
$\geq 3$ years & $51(17.3)$ & $179(60.7)$ & $230(78.0)$ \\
Training sessions per week & & $34(11.5)$ \\
$1-2$ h/week & $9(13.8)$ & $25(10.9)$ & $94(31.9)$ \\
$3-5$ h/week & $10(15.4)$ & $84(36.5)$ & $167(56.6)$ \\
$\geq 5$ h/week & $46(70.8)$ & $121(52.6)$ & $74(25.1)$ \\
Previous training on prevention and management of orofacial injuries \\
Yes & $28(43.1)$ & $46(20.0)$ & $221(74.9)$ \\
\hline No & $37(56.9)$ & $184(80.0)$ & \\
\hline
\end{tabular}

athletes were stocks $(n=117,39.7 \%)$ and mouth-formed mouthguards $(n=90,30.5 \%)$. Only $3.7 \%(n=11)$ of the participants reported the use of custom-made mouthguards. Table 3 shows more details about mouthguard use among athletes. The most common reasons for not using a mouthguard included the annoying feeling they caused ( $n=43,44.3 \%$ ), lack of knowledge about the preventive role of mouthguards against TDIs $(n=18,18.6 \%)$, and believing in the ineffective of mouthguards $(n=12$, 12.4\%) (Fig. 1).

The mean score of self-reported preventive practice was $3.53 \pm 1.82$ (range: $0-7$ ). The question: "Do you wear a mouthguard during training or a match?" was answered favorably by $71.5 \%(n=211)$ of the respondents and the question: "Do you lend your mouthguard?" was answered favorably by $70.8 \%(n=209)$ of athletes; these two questions had the highest number of favorable answers. Conversely, choosing "What type of mouthguard do you use?" by $3.7 \%(n=11)$ was the least favorable answer (custom-made mouthguard) (Table 3 ).

The mean score of the knowledge of emergency management of orofacial injuries was $1.67 \pm 1.10$ (range: $0-5$ ). The most common correct answer was for the question: "What will you do if your tooth becomes loose due to trauma?" ( $n=204,69.2 \%)$, and the least common correct answers were for the question: "What will you do in case of tooth avulsion due to trauma?" ( $\mathrm{n}=15,5.1 \%)$ and "In case of tooth avulsion, how much time do you think you have to put it back in?" ( $n=15,5.1 \%)$ (Table 4$)$.

The score of self-reported preventive practice had a significant relationship with age $(\beta=0.19, p=0.002)$ and self-reported experience of orofacial injuries $(\beta=-0.15$, $p=0.010)$. Moreover, gender $(\beta=0.11, p=0.048)$ and exercise time per week $(\beta=0.15, p=0.012)$ had significant relationships with the knowledge score; female athletes and athletes who exercised more per week had more knowledge score on management of orofacial injuries (Table 5).

The Pearson correlation coefficient showed that selfreported practice had a weak correlation with knowledge $(\mathrm{r}=0.16, p=0.006)$.

Table 2 Results of linear regression model controlling for demographics on factor associated with athletes' self-reported experience of orofacial injuries $(n=295)$

\begin{tabular}{lcrr}
\hline & Unstandardized coefficients & Standardized coefficients $^{\text {a }}$ & $\boldsymbol{p}$ value $^{-}$ \\
\hline Self-reported experience of orofacial injuries & & -0.3 & $<0.001$ \\
Age & -0.8 & 0.1 & 0.049 \\
Type of sport & 0.1 & 0.1 & 0.037 \\
Training sessions per week & 0.1 & -0.1 & 0.010 \\
Previous training on orofacial injuries & -0.2 & \\
\hline
\end{tabular}

${ }^{\text {a }}$ Scale-standardized 
Table 3 Participants' answers to the questions of self-reported preventive practice regarding orofacial injuries $(n=295)$

\begin{tabular}{|c|c|c|c|}
\hline & $\begin{array}{l}\text { Karate } \\
\text { n (\%) }\end{array}$ & $\begin{array}{l}\text { Taekwondo } \\
\text { n (\%) }\end{array}$ & $\begin{array}{l}\text { Total } \\
\mathrm{n}(\%)\end{array}$ \\
\hline \multicolumn{4}{|c|}{ Do you wear a mouthguard during training or match? } \\
\hline Yes $^{\mathrm{a}}$ & $53(81.5)$ & $158(68.7)$ & $211(71.5)$ \\
\hline No & $12(18.5)$ & $72(31.3)$ & $84(28.5)$ \\
\hline \multicolumn{4}{|c|}{ What type of mouthguard do you use $e^{b}$} \\
\hline Custom made & $4(6.2)$ & $7(3.2)$ & $11(3.7)$ \\
\hline mouth-formed & $23(35.4)$ & $67(29.1)$ & $90(30.5)$ \\
\hline Stock & $29(44.6)$ & $8(38.3)$ & $117(39.7)$ \\
\hline \multicolumn{4}{|c|}{ Do you lend your mouthguard? } \\
\hline Yes & $9(13.8)$ & $4(1.7)$ & $13(14.4)$ \\
\hline $\mathrm{No}^{\mathrm{a}}$ & $46(70.8)$ & $163(70.9)$ & $209(70.8)$ \\
\hline \multicolumn{4}{|c|}{ When do you wear your mouthguard? } \\
\hline Training only & $4(6.2)$ & $3(1.3)$ & $7(2.4)$ \\
\hline Matches only & $37(56.9)$ & $91(39.6)$ & $128(43.4)$ \\
\hline Training and matches ${ }^{\mathrm{a}}$ & $9(13.8)$ & $79(34.3)$ & $88(29.8)$ \\
\hline $\begin{array}{l}\text { Only when parents or } \\
\text { coach tell me }\end{array}$ & $5(7.7)$ & $11(4.8)$ & $16(5.4)$ \\
\hline \multicolumn{4}{|c|}{ Do you wear protective headgear? } \\
\hline$Y_{e s}^{\mathrm{a}}$ & $11(16.9)$ & $191(83.0)$ & $202(68.5)$ \\
\hline No & $54(83.1)$ & $39(17.0)$ & $93(31.5)$ \\
\hline
\end{tabular}

${ }^{\text {a }}$ Favorable answers

${ }^{\mathrm{b}}$ In this question the answers had weighted scores (custom-made $=3$, mouthformed $=2$, stock $=1$ ); there were some respondents who reported no usage of mouthguard

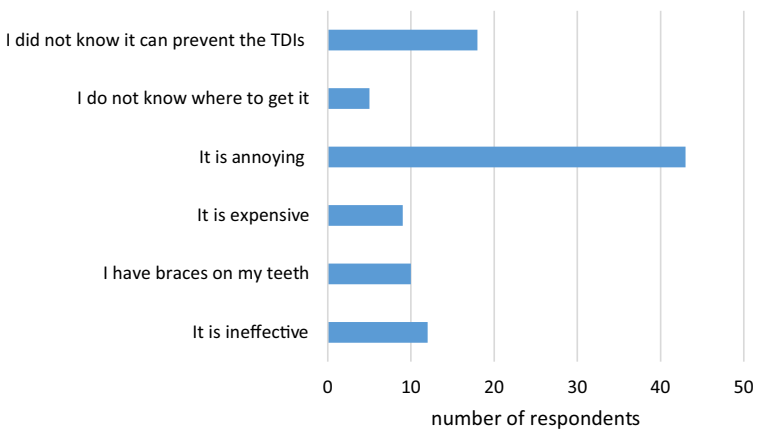

Fig. 1 Reasons for not using the mouthguard stated by athletes $(n=97)$

\section{Discussion}

The present study was conducted to evaluate selfreported experience of orofacial injuries, self-reported preventive practice, and knowledge of emergency management of sports-related orofacial injuries in adolescent martial arts athletes (Karate and Taekwondo). The results showed that self-reported preventive practice of athletes was moderate while their knowledge of management of orofacial injuries was inadequate. Moreover, the prevalence of previous orofacial injury was relatively high with no difference between males and females. Furthermore, older athletes, athletes with fewer training sessions per week, and those with previous training on prevention and management of orofacial injuries had less experience of orofacial injuries.

In the present study, $62 \%$ of the participants reported the history of at least one orofacial injury, which was rather high in young Iranian athletes. This finding was similar to a study by Bolhius et al. (62-68\%) who evaluated orofacial injuries in field hockey players [26]. However, some studies have found lower rates of orofacial injuries; for instances, about $20 \%$ of $8-26$ year-old Croatian Taekwondo athletes [27], 14\% of Croatian Taekwondo players [8], $50 \%$ of Catalonian [28], $16 \%$ of Dutch field hockey players [29], and $49 \%$ of Croatian professional handball players [30] had experienced orofacial injuries. Different contact sports may pose different risks of oral and dental injuries; thus, based on the risk of orofacial injuries, Federation Dentaire International has categorized sports into high- and medium-risk sports. High-risk sports include American football, hockey, ice hockey, lacrosse, martial arts, rugby, ice skating, skateboarding and mountain biking. Medium-risk sports include basketball, soccer, handball, diving, squash, gymnastics, parachuting, and water polo [3]. Moreover, the occurrence of sports-related orofacial injuries depends on various factors such as the type of the sport, geographical location, age, sample size, level of competition, rules on safety equipment usage, and exposure time [3, 31, 32]. Whilst these differences may be explained by cultural and age diversities within various groups, the methodology of the studies would likely have a significant impact as well.

The present study found no significant difference in the history of orofacial injuries between males and females, which was similar to the findings of Vidovic et al. in Croatian Taekwondo athletes [27], and Zaleckiene et al. in 11-13 year-old Lithuanian schoolchildren [32]. Some previous studies showed that males experienced more trauma compared to females [33-35]. It has been suggested that males tend to take part in contact sports and violent behaviors more than females do [2, 19]. However, gender differences appear to be fading as more females are participating in sports including contact sports $[19,20]$. Traebert et al. suggested that females could be exposed to the same risk factors for orofacial injuries as men [20].

The results showed that younger players experienced orofacial injuries more frequently compared to older players. Different studies have shown that the majority of orofacial injuries occur in the age group 9-12 years [2, 19]. Moreover, it has been found that amateur athletes 
Table 4 Participants' answers to the questions on knowledge of emergency management of orofacial injuries $(n=295)$

\begin{tabular}{|c|c|c|c|}
\hline & Karate & Taekwondo & Total \\
\hline \multicolumn{4}{|l|}{ What will you do if a part of your tooth is broken and you find the broken part? } \\
\hline I will come to dentist with broken piece of my tooth ${ }^{\mathrm{a}}$ & $42(64.6)$ & $105(45.7)$ & $147(49.8)$ \\
\hline I will just go to dentist without broken piece & $10(15.4)$ & $26(11.3)$ & $36(12.2)$ \\
\hline I do not know & $13(20.0)$ & $99(43.0)$ & $112(38.0)$ \\
\hline \multicolumn{4}{|c|}{ In previous situation, the broken piece of tooth should be kept in which of the followings? } \\
\hline Paper tissue & $36(55.4)$ & $73(31.7)$ & $109(36.9)$ \\
\hline Water/milk ${ }^{\mathrm{a}}$ & $14(21.5)$ & 45 (19.6) & $59(20.0)$ \\
\hline Dry container & $1(1.5)$ & $9(3.9)$ & $10(3.4)$ \\
\hline I don't know & $11(16.9)$ & $96(41.7)$ & $107(36.3)$ \\
\hline \multicolumn{4}{|l|}{ What will you do if your tooth become loose by hit? } \\
\hline I will go to dentist at same day ${ }^{a}$ & $42(64.6)$ & $162(70.4)$ & $204(69.2)$ \\
\hline It does not need to examine by dentist & $8(12.3)$ & $24(1.4)$ & $32(10.8)$ \\
\hline I don't know & $15(23.1)$ & $44(19.1)$ & $59(20.0)$ \\
\hline \multicolumn{4}{|l|}{ What will you do if your tooth is completely knocked out by hit? } \\
\hline I will find the tooth, wash it with soap, and go to dentist & $10(15.4)$ & $26(11.3)$ & $36(12.2)$ \\
\hline I will find the tooth, put it in its place in my mouth, and go to dentist ${ }^{\mathrm{a}}$ & $3(14.6)$ & $12(5.2)$ & $15(5.1)$ \\
\hline I will not look for the tooth and go to dentist quickly & $17(26.2)$ & $24(10.4)$ & $41(13.9)$ \\
\hline I will find the tooth, put in in a napkin, and go to dentist & $26(40.0)$ & $115(50.0)$ & $141(47.8)$ \\
\hline I do not know & $9(13.8)$ & $53(23.0)$ & $62(21.0)$ \\
\hline \multicolumn{4}{|l|}{ What will you do if your tooth completely knocked out and become dirty? } \\
\hline I will wash it with toothbrush slowly & $19(29.2)$ & $65(28.3)$ & $84(28.5)$ \\
\hline I will wash it with water ${ }^{a}$ & $15(23.1)$ & $52(22.6)$ & $67(22.7)$ \\
\hline I will put the tooth back in mouth without any manipulation & $3(4.6)$ & $5(2.2)$ & $8(2.7)$ \\
\hline I will wash it with soap & $14(21.5)$ & $21(9.1)$ & $35(11.9)$ \\
\hline I do not know & $14(21.5)$ & $87(37.8)$ & $101(34.2)$ \\
\hline \multicolumn{4}{|c|}{ In case of a knocked out tooth, how much time do you think you have to put it back in? } \\
\hline $15 \mathrm{~min}$ & $8(12.3)$ & $19(8.3)$ & $27(9.2)$ \\
\hline $30 \min ^{\mathrm{a}}$ & $3(4.6)$ & $12(5.2)$ & $15(5.1)$ \\
\hline $1 \mathrm{~h}$ & $3(4.6)$ & $9(3.9)$ & $12(4.1)$ \\
\hline Only a dentist can put it back & $51(78.5)$ & $190(82.6)$ & $241(81.7)$ \\
\hline \multicolumn{4}{|l|}{ If a tooth gets knocked out what would you put it in? } \\
\hline Water & $17(26.2)$ & $30(13)$ & $47(15.9)$ \\
\hline Milk $^{\mathrm{a}}$ & $5(7.7)$ & $41(17.8)$ & $46(15.6)$ \\
\hline Paper tissue & $36(55.4)$ & $105(45.7)$ & $141(47.8)$ \\
\hline Sports drink & $1(1.5)$ & $0(0.0)$ & $1(0.3)$ \\
\hline Nothing & $5(7.7)$ & 25 (10.9) & $30(10.2)$ \\
\hline I do not know & $1(1.5)$ & $29(12.6)$ & $30(10.2)$ \\
\hline
\end{tabular}

${ }^{a}$ Correct answers

suffer from orofacial injuries more often compared to professionals $[3,16]$. The most likely reasons may be lack of professional athletic skills in amateurs and improper use of mouthguards compared to professional athletes. Besides, the more hours of training per week in our study was associated with more self-reported experience of orofacial injuries. Furthermore, the results showed that previous training on prevention and management of orofacial injuries was associated with reduced history of orofacial injuries. Even a short-term training course for non-professional population may improve their knowledge [18]; therefore, the more knowledge, the better the practice, which can lead to less orofacial injury.

In the present study, $71.5 \%$ of the participants indicated that they usually wore a mouthguard during a match or practice, which was higher than Korean taekwondo athletes (56\%) [36], and Saudi taekwondo athletes (56\%) [37]. However, Vivovic et al. reported mouthguard use by $96 \%$ of young Taekwondo athletes [27]. Bergman et al. studied professional handball players and found that regular 
Table 5 Results of linear regression model controlling for demographics on factor associated with athletes' self-reported preventive practice and knowledge regarding orofacial injuries $(n=295)$

\begin{tabular}{lccc}
\hline & $\begin{array}{l}\text { Unstandardized } \\
\text { coefficients }\end{array}$ & $\begin{array}{l}\text { Standardized } \\
\text { coefficients }^{\mathbf{a}}\end{array}$ & $\boldsymbol{p}$ value \\
\hline $\begin{array}{l}\text { Self-reported preventive practice } \\
\text { Age }\end{array}$ & 0.2 & 0.2 & 0.002 \\
$\begin{array}{l}\text { Self-reported experi- } \\
\text { ence of orofacial injuries }\end{array}$ & -0.6 & -0.2 & 0.010 \\
Knowledge & 0.3 & & \\
Gender & 0.2 & 0.1 & 0.048 \\
Exercise time per week & 0.2 & 0.2 & 0.012 \\
\hline
\end{tabular}

${ }^{a}$ Scale-standardized

use of the mouthguard would reduce the chance of dental injury by 5.55 times [30]. Sepet et al. found that whilst $41.1 \%$ of participants understood the real possibility of orofacial injuries in sports and $55.4 \%$ were aware of the protective effect of mouthguards, only $11.2 \%$ of the participants reported routine mouthguard use [38]. Same findings by Galic et al. showed that although most of the participants were aware of the protective benefits of wearing a mouthguard in reducing sports-related injuries, only $41 \%$ of them actually used it [8].

The athletes' attitude and perceptions about wearing mouthguards and its comfort influences their compliance [9]. In our study, the most common reason for lack of mouthguard use was the annoying feeling it caused, which was similar to other studies [27, 36-38]. This may be because of the type of the mouthguard used: in the present study, only $3.7 \%$ of the participants wore custom-made mouthguards while $39.7 \%$ of participants wore stock mouthguards and $30.5 \%$ used mouth-formed mouthguards. These findings were similar to a study by Vidovic et al. that found that only $5.3 \%$ of the participants used custom-made mouthguards [27]. Moreover, these findings are consistent with other studies investigating the use of different mouthguard types in other contact sports, such as studies conducted by Biagi et al. [39], Emerich et al. [40], and Andrade et al. [41]. In many studies, athletes reported that using stocks or mouthformed mouthguards caused breathing and speaking problems or jaw and muscle fatigue, or they fell out or became dislodged during use; however, these problems were minimal in custom-made mouthguards because this type fits well with the gums and teeth $[21,27,28,30$, 36]. Although custom-made mouthguards are relatively expensive, which is a significant barrier against their wide use, the treatment cost and frequency of TDIs are considerable indicating the importance of prevention of TDIs in the best possible way [3]. Therefore, the American Academy of Pediatric Dentistry and the Academy for Sports Dentistry have recommended the use of custom-made mouthguards in all activities with a risk of TDIs $[9,12]$. Another barrier against mouthguard use is poor compliance of athletes $[9,42]$; however, mouthguard use recommendation by dentists would encourage their use and improve the athletes' compliance [30].

The outcome of orofacial injury treatment depends not only on the knowledge and skills of the dentists but also on the emergency aid available at the site of the injury $[3,19]$. Particularly, in case of tooth avulsion as a dental emergency, early and accurate management is necessary to have the most successful outcome [17]. It is therefore important that athletes and coaches have basic knowledge about how to deal with emergency TDIs [3, 19]. In our study, the athletes' knowledge score was generally low; the poorest answers were related to the management of tooth avulsion as only $5 \%$ of respondents were aware of the possibility of replantation of an avulsed tooth, and less than one quarter of them indicated that using water was sufficient to clean the contaminants of an avulsed tooth. Generally, these findings are in accordance with similar studies that showed low knowledge levels of athletes regarding management of TDIs, particularly tooth avulsion [8, 37-39, 43, 44]. This is a worrying finding that requires the dental professionals to interact with the sports community to improve their awareness regarding prevention and management of sports-related orofacial injuries. Dentists could play an important role in educating athletes by demonstrating the benefits of using custom-made mouthguards and encouraging them to use one. Many studies have suggested education as a preventive measure to improve athletes' knowledge of prevention and emergency management of TDIs [8, 38, 39, 45]; this goal can be easily achieved using different methods such as professional lectures, video materials, and/or text materials such as posters and leaflets.

To the best of our knowledge, this was the first study of the preventive practice of Iranian adolescent athletes regarding orofacial injuries and their awareness about the management of TDIs. The participation of a high number of female adolescence athletes was one of the main strengths of this study. However, this study had some limitations. Similar to other questionnaire-based studies, athletes were required to remember their mouthguard use and previous injuries, which increased the possibility of recall bias and social desirability. Furthermore, the questionnaires did not consider the fact that some individuals might have started using a mouthguard after an orofacial trauma [10]. However, the findings are valuable in developing preventive strategies in sports activities for young athletes. 


\section{Conclusion}

The study showed a relatively undesirable preventive practice and distinct lack of knowledge regarding the emergency management of orofacial injuries. The main reason for not using mouthguards was the annoying feeling they caused, probably because most of the athletes used stocks or mouth-formed mouthguards that were unfitted. It seems that provision of education by dentists to all people who interact with young athletes, including parents, teachers, coaches, and the athletes themselves is vital to promote oral health in athletes. Making mouthguard use compulsory in sports with a medium risk of orofacial injuries is as important as that in high-risk sports. The high occurrence of self-reported orofacial injuries indicates the importance of more education and stricter rules for the athlete population.

\section{Abbreviations}

TDIs: Traumatic dental injuries; COVID-19: Coronavirus disease of 2019; SPSS: Statistical package for the social science.

\section{Acknowledgements \\ This study was funded and supported by Tehran University of Medical Sci- ences (TUMS); Grant No. 99.2.133.48370. We are highly thankful to the Depart- ment of Sports Medicine of Tehran University of Medical Sciences, Iran Sports Medicine Federation, Iran Karate Federation, and Iran Taekwondo Federation for helping and supporting us in this study. We would like to thank Dr. Farhad Moradi Shahpar, Dr. Laleh Hakemi, Dr. Mohammadebrahim Marjani, Farahnaz Arbab, Hossein Parsi, and Hasan Shokrian for assisting us in collecting data.}

\section{Authors' contributions}

All authors were involved in the conception and design of the study. A.E. carried out data collection; S.M and S.R. performed interpretation of the data. All authors participated in either drafting or critical revising the manuscript. All authors read and approved the final manuscript.

\section{Funding}

This study was funded and supported by Tehran University of Medical Sciences (TUMS); Grant No. 99.2.133.48370.

\section{Availability of data and materials}

Not applicable.

\section{Declarations}

\section{Ethics approval and consent to participate}

Ethical approval was obtained from the Ethics Committee of Tehran University of Medical Sciences (IR.TUMS.DENTISTRY.REC.1399.016). The study was voluntary and the responses were anonymous. All the participants were informed about the objectives of the study. Informed consent was obtained from participants and their parents via a link sent to the parent's cellphone.

\section{Consent for publication}

Not applicable.

\section{Competing interests}

The authors declare that they have no competing interests.

\section{Author details}

${ }^{1}$ School of Dentistry, Tehran University of Medical Sciences, Tehran, Iran. ${ }^{2}$ Research Center for Caries Prevention, Dentistry Research Institute, Tehran University of Medical Sciences, Tehran, Iran. ${ }^{3}$ Department of Community Oral Health, School of Dentistry, Tehran University of Medical Sciences, Tehran, Iran.
${ }^{4}$ Sports Medicine Research Center, Neuroscience Institute, Tehran University of Medical Sciences, Tehran, Iran. ${ }^{5}$ Iran Sports Medicine Federation, Tehran, Iran. ${ }^{6}$ Department of Pediatric Dentistry, Faculty of Dentistry, Ilam University of Medical Sciences, Ilam, Iran.

Received: 24 April 2021 Accepted: 18 October 2021

Published online: 26 October 2021

\section{References}

1. Petti S, Glendor U, Andersson L. World traumatic dental injury prevalence and incidence, a meta-analysis_one billion living people have had traumatic dental injuries. Dent Traumatol. 2018;34(2):71-86.

2. Navabazam A, Farahani SS. Prevalence of traumatic injuries to maxillary permanent teeth in 9-to 14-year-old school children in Yazd. Iran Dent Traumatol. 2010;26(2):154-7.

3. Glendor U. Aetiology and risk factors related to traumatic dental injuriesa review of the literature. Dent Traumatol. 2009;25(1):19-31.

4. Khoshnevisan M, Ghasemianpour M, Samadzadeh H, Baez R. Oral health status and healthcare system in IR Iran. J Contemp Med Sci. 2018;4(3):107-18.

5. Tuna EB, Ozel E. Factors affecting sports-related orofacial injuries and the importance of mouthguards. Sports Med. 2014:44(6):777-83.

6. Young EJ, Macias CR, Stephens L. Common dental injury management in athletes. Sports Health. 2015;7(3):250-5.

7. Halabchi F, Ziaee V, Lotfian S. Injury profile in women shotokan karate championships in iran (2004-2005). J Sports Sci Med. 2007;6(CSSI-2):52.

8. Galic T, Kuncic D, Poklepovic Pericic T, Galic I, Mihanovic F, Bozic J, et al. Knowledge and attitudes about sports-related dental injuries and mouthguard use in young athletes in four different contact sports - water polo, karate, taekwondo and handball. Dent Traumatol. 2018;34(3):175-81.

9. American Academy of Pediatric Dentistrty. Policy on prevention of sports-related orofacial injuries. Available from: https://www.aapd.org/ media/policies guidelines/p sports.pdf. Accessed 20 Apr 2021.

10. Knapik JJ, Hoedebecke BL, Rogers GG, Sharp MA, Marshall SW. Effectiveness of Mouthguards for the prevention of orofacial injuries and concussions in sports: systematic review and meta-analysis. Sports Med. 2019;49(8):1217-32

11. Kroon J, Cox JA, Knight JE, Nevins PN, Kong WW. Mouthguard use and awareness of junior rugby league players in the Gold Coast, Australia: a need for more education. Clin J Sport Med. 2016;26(2):128-32.

12. Academy for Sports Dentistry. Gear up right. Get a custom mouthguard. Available from: https://www.academyforsportsdentistry.org/assets/docs/ mouthguard\%20flyer\%20text\%20only\%20with\%20logo\%20athlete\% 20resources.pdf. Accessed 20 Apr 2021.

13. Koutures C, Demorest RA. Participation and injury in martial arts. Curr Sports Med Rep. 2018;17(12):433-8.

14. Demorest RA, Koutures C. Youth participation and injury risk in martial arts. Pediatrics. 2016;138(6):e20163022

15. Ziaee V, Rahmani S-H, Rostami M. Injury rates in Iranian taekwondo athletes; a prospective study. Asian J Sports Med. 2010;1(1):23.

16. Ziaee V, Shobbar M, Lotfian S, Ahmadinejad M. Sport injuries of karate during training: an epidemiologic study in Iran. Asian J Sports Med. 2015. https://doi.org/10.5812/asjsm.26832.

17. Lam R. Epidemiology and outcomes of traumatic dental injuries: a review of the literature. Aust Dent J. 2016:61:4-20.

18. Levin L, Zadik Y. Education on and prevention of dental trauma: it's time to act! Dent Traumatol. 2012;28(1):49-54.

19. Zaleckiene V, Peciuliene V, Brukiene V, Drukteinis S. Traumatic dental injuries: etiology, prevalence and possible outcomes. Stomatologija. 2014;16(1):7-14.

20. Traebert J, Bittencourt DD, Peres KG, Peres MA, De Lacerda JT, Marcenes W. Aetiology and rates of treatment of traumatic dental injuries among 12-year-old school children in a town in southern Brazil. Dent Traumatol. 2006;22(4):173-8.

21. Rouhani A, Akbari M, Ghoddusi J, Rahmandust M. Knowledge of sportsmen and coaches about dental trauma in 2011 in Mashhad. J Isfahan Dent Sch. 2015;11(3):239-47. 
22. Nagata JY, de Andrade Góis VL, Münchow EA, Albuquerque MTP. Dental trauma education intervention as a positive influence among undergraduate students. Eur J Dent. 2018;12(4):502.

23. McHugh ML. Interrater reliability: the kappa statistic. Biochem Med. 2012;22(3):276-82.

24. Duruk G, Erel ZB. Assessment of Turkish dentists' knowledge about managing avulsed teeth. Dent Traumatol. 2020;36(4):371-81.

25. McIntyre JD, Lee JY, Trope M, Vann WF Jr. Effectiveness of dental trauma education for elementary school staff. Dent Traumatol. 2008;24(2):146-50.

26. Bolhuis J, Leurs J, Flögel G. Dental and facial injuries in international field hockey. Br J Sports Med. 1987;21(4):174-7.

27. Vidovic D, Bursac D, Skrinjaric T, Glavina D, Gorseta K. Prevalence and prevention of dental injuries in young taekwondo athletes in Croatia. Eur J Paediatr Dent. 2015;16:107.

28. Zamora-Olave C, Willaert E, Parera L, Riera-Puñet N, Martinez-Gomis J. Experience with mouthguards and prevalence of orofacial injuries among field hockey players in Catalonia. Dent Traumatol. 2020;36(3):285-90.

29. Vucic S, Drost RW, Van Wijk AJ, Wesselink PR, Wolvius EB. Patterns of orodental injury and mouthguard use in Dutch field hockey. Br J Sports Med. 2016:50(11):661-8.

30. Bergman L, Milardović Ortolan S, Žarković D, Viskić J, Jokić D, Mehulić K. Prevalence of dental trauma and use of mouthguards in professional handball players. Dent Traumatol. 2017;33(3):199-204.

31. Tsuchiya S, Tsuchiya M, Momma H, Sekiguchi T, Kuroki K, Kanazawa K, et al. Factors associated with sports-related dental injuries among young athletes: a cross-sectional study in Miyagi prefecture. BMC Oral Health. 2017:17(1):1-9.

32. Zaleckienè $V$, Pečiulienè $V$, Aleksejūnienè J, Drukteinis $S$, Brukienè $V$. Denta trauma experience, attitudes and trauma prevention in 11-to 13-year-old Lithuanian schoolchildren. Oral Health Prev Dent. 2020;18(2):373-8.

33. Dhillon BS, Sood N, Sood N, Sah N, Arora D, Mahendra A. Guarding the precious smile: incidence and prevention of injury in sports: a review. J Int Oral Health. 2014;6(4):104.

34. Aren G, Sepet E, PInar Erdem A, Tolgay CG, Kuru S, Ertekin C, et al. Predominant causes and types of orofacial injury in children seen in the emergency department. Ulus Travma Acil Cerrahi Derg. 2013;19(3):246-50.
35. Azodo CC, Odai CD, Osazuwa-Peters N, Obuekwe ON. A survey of orofacial injuries among basketball players. Int Dent J. 2011;61(1):43-6.

36. Lee J-W, Heo C-K, Kim S-J, Kim G-T, Lee D-W. Mouthguard use in Korean Taekwondo athletes-awareness and attitude. J Adv Prosthodont. 2013;5(2):147.

37. Aljohani YR, Alfaifi KH, Redwan SK, Sabbahi DA, Zahran MH. Dental injuries in taekwondo athletes practicing in Saudi Arabia. Saudi Med J. 2017;38(11):1143

38. Sepet E, Aren G, Dogan Onur O, Pinar Erdem A, Kuru S, Tolgay CG, et al. Knowledge of sports participants about dental emergency procedures and the use of mouthguards. Dent Traumatol. 2014;30(5):391-5.

39. Biagi R, Cardarelli F, Butti A, Salvato A. Sports-related dental injuries: knowledge of first aid and mouthguard use in a sample of Italian children and youngsters. Eur J Paediat Dent. 2010;11(2):66-70.

40. Emerich K, Nadolska-Gazda E. Dental trauma, prevention and knowledge concerning dental first-aid among Polish amateur boxers. J Sci Med Sport. 2013;16(4):297-301.

41. Andrade RA, Evans PLS, Almeida ALS, Silva JJRd, Guedes AML, Guedes FR, et al. Prevalence of dental trauma in Pan American games athletes. Dent Traumatol. 2010:26(3):248-53.

42. Matalon V, Brin I, Moskovitz M, Ram D. Compliance of children and youngsters in the use of mouthguards. Dent Traumatol. 2008;24(4):462-7.

43. Al-Arfaj I, Al-Shammari A, Al-Subai T, Al-Absi G, AlJaffari M, Al-Kadi A, et al. The knowledge, attitude and practices of male sports participants to sports-related dental trauma in Khobar and Dammam, Saudi Arabia: a pilot survey. Saudi Dent J. 2016;28(3):136-41.

44. Mori GG, de Mendonça Janjácomo DM, Castilho LR, Poi WR. Evaluating the knowledge of sports participants regarding dental emergency procedures. Dent Traumatol. 2009:25(3):305-8.

45. Pieter W. Martial arts injuries. Med Sport Sci. 2005;48:59-73.

\section{Publisher's Note}

Springer Nature remains neutral with regard to jurisdictional claims in published maps and institutional affiliations.
Ready to submit your research? Choose BMC and benefit from:

- fast, convenient online submission

- thorough peer review by experienced researchers in your field

- rapid publication on acceptance

- support for research data, including large and complex data types

- gold Open Access which fosters wider collaboration and increased citations

- maximum visibility for your research: over 100M website views per year

At BMC, research is always in progress.

Learn more biomedcentral.com/submissions 